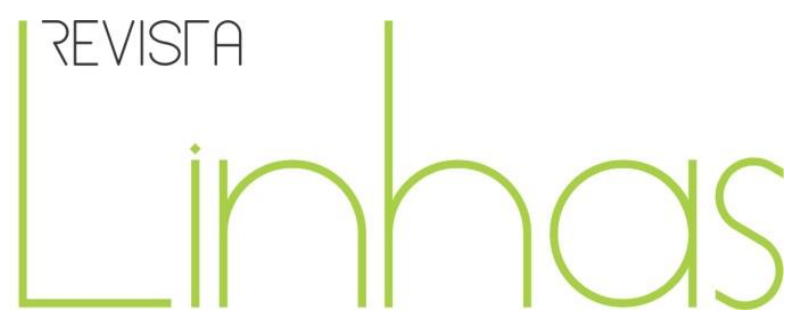

\title{
O reconhecimento oficial de artistas mulheres no campo artístico em Curitiba/PR (2000-2011)
}

\section{Resumo}

Este artigo apresenta as mulheres que conquistaram o mercado oficial da arte em Curitiba/PR. A partir do conceito de trajetória de Pierre Bourdieu, delinearam-se os valores comercial, simbólico e oficial, considerando o percurso das artistas locais no período entre 2000 e 2011. A finalidade deste artigo é compreender qual foi a representatividade delas em comparação à produção de artistas homens, apresentando pontos das trajetórias que as conduziram ou não ao reconhecimento oficial. Na instância simbólica, o número de artistas homens é superior ao de artistas mulheres, apenas 11 delas têm suas obras pertencentes ao acervo do Museu Oscar Niemeyer (MON), com produção que atende ao perfil apresentado por Luciana Loponte, mostrando que o campo artístico ainda é hierarquizado e sexista nos termos de Rui Fonseca. Consequentemente, uma parcela das obras analisadas não simboliza uma pauta feminista, já que os temas, as formas e as cores comunicam uma docilidade. Tem-se a imagem de uma arte dócil, nas entrelinhas, e em sua dubiedade como mulheres artistas, o repertório imagético preserva o estereótipo de que o conhecimento da arte para as mulheres é um deleite e não uma profissão; embora as mulheres que conquistaram o mercado oficial compreenderam as regras do campo da arte ao transitarem em diferentes espaços sociais, ocupando várias posições no campo artístico, educacional e cultural.

Palavras-chave: Artes visuais; gênero; feminismo; arte paranaense.

\author{
Adriana Vaz \\ Universidade Federal do Paraná - \\ UFPR - Curitiba/PR - Brasil \\ vazufpr@gmail.com
}

\footnotetext{
Para citar este artigo:

VAZ, Adriana. O reconhecimento oficial de artistas mulheres no campo artístico em Curitiba/PR (2000-2011). Revista Linhas. Florianópolis, v. 22, n. 49, p. 344-372, maio/ago. 2021.
} 


\title{
Official recognition of female artists in the artistic field of Curitiba/PR (2000-2011)
}

\begin{abstract}
This article presents the female artists who conquered the official market in Curitiba / PR. Based on the concept of Pierre Bourdieu's trajectory, the commercial, symbolic and official values were outlined, considering the path of local artists in the period between 2000 and 2011. The purpose is to understand the representativeness of female artists in the artistic field in Curitiba compared to the production of male artists, presenting points of the trajectories of these women that lead, or not, to official recognition. In short, in the symbolic instance, the number of male artists is higher than that of female artists, in addition, only 11 women have their works belonging to the collection of the Oscar Niemeyer Museum (MON) with production that meets the profile presented by Luciana Loponte and shows that the artistic field is still hierarchical and sexist in terms of Rui Fonseca. Consequently, a portion of the analyzed works does not symbolize a feminist agenda, since the themes, shapes and colors communicate a docility. One has the image of a docile art, between the lines, and in its dubiousness as women-artists, the imagery repertoire preserves the stereotype that knowledge of art for women is a delight and not a profession; although, the women who conquered the official market understood the rules of the field of art when traveling in different social spaces occupying various positions in the artistic, educational and cultural fields.
\end{abstract}

Keywords: Visual arts; gender; feminism; art from Paraná. 
O presente estudo trata do sistema de arte em Curitiba a partir da produção de artes visuais com ênfase na produção bidimensional dos artistas, homens e mulheres, existentes nas galerias de arte classificadas como comercial, intermediária e de vanguarda (VAZ, 2004) juntamente ao estudo sobre o público do MON (Museu Oscar Niemeyer), em que parte da discussão versa sobre a constituição do acervo (VAZ, 2011).

Quanto ao recorte temporal, o texto foi elaborado a partir de dados empíricos, construídos ao revisitar as pesquisas de mestrado e doutorado defendidas pelo autor em 2004 e 2011, respectivamente, o que em parte justifica a combinação de dois períodos distintos: o primeiro de 2000 a 2003 e o segundo de 2003 a 2011.

Neste artigo, para mensurar a representatividade ou não das mulheres no campo artístico em Curitiba, fez-se um corte em suas trajetórias, escolhendo espaços específicos em que transitaram pelo universo da arte (galerias, exposições, museus), visto que "cada agente do campo é caracterizado por sua trajetória social, seu habitus e sua posição no campo." (CATANI, 2011, p. 193, grifo do autor).

O objetivo é compreender qual é a representatividade de artistas mulheres no campo artístico em Curitiba em comparação à produção de artistas homens. Para mapear em que proporção elas conquistam espaço no circuito oficial, articulam-se pontos de sua trajetória: a validade comercial do mercado das galerias, a consagração simbólica pela participação em exposições de vanguarda, a comercialização das obras nas galerias de vanguarda e, por fim, o reconhecimento oficial do Estado pela produção pertencer ao acervo do MON.

O artigo está ancorado no conceito de trajetória e na problemática do coeficiente negativo, atribuído ao gênero feminino de Pierre Bourdieu (2009 e 1996), situação que precisa ser historicizada para que se rompa o ciclo de dominação entre os gêneros. Articula-se com as contribuições de Rui Fonseca (2013b), que trata da representatividade da produção feminista no circuito artístico comercial e menciona a predominância de homens como legitimadores culturais em postos de alto escalão no campo da arte em nível internacional - questão problematizada por Luciana Loponte, quando alude que a 
história da arte e seus bens de consumo adota como "verdade" o olhar masculino, em que a mulher é vista como “objeto de contemplação”.

Pelo estudo sociológico da produção das galerias de arte e da posição do Estado como mediador cultural frente ao MON, na categoria de OSCIP (Organização da Sociedade Civil de Interesse Público), concorda-se com as colocações de Fonseca (2013b), quando menciona que o mercado da arte é orquestrado por vários agentes sociais, nem sempre ligados ao mundo da arte, em que a aceitação oficial da arte feminista no sentido comercial é vista pelo viés masculino. A arte pela visão masculina traduz-se em investimento, com isso a cotação da produção de artistas mulheres, feministas em especial, é irrisória quando comparada à valorização da produção feita pelos artistas homens.

Para discutir a produção de artistas mulheres no campo artístico de Curitiba, destacam-se três fontes: a produção de artistas residentes em Curitiba e com obras em linguagem bidimensional, expostas no período de 2000 a 2003 nas galerias comerciais, intermediárias e de vanguarda; o mapeamento das artistas de três exposições de vanguarda, realizadas no período entre 2000 e 2002, uma pela FCC (Fundação Cultural de Curitiba) e duas pela SEEC (Secretaria de Estado da Cultura do Paraná); as artistas que compõem o acervo artístico do MON - dividido em produção local, nacional e internacional - entre 2003 e 2011.

A combinação das fontes citadas resulta da junção de dados coletados em dois momentos distintos de pesquisa: o primeiro estudo tratava de classificar as tipologias das galerias de arte e o pertencimento dos artistas no mercado das artes visuais em Curitiba/PR, tendo como um dos parâmetro de análise o vínculo dos artistas nas galerias ativas em 2004, assim como nas exposições de arte realizadas entre 2000 a 2003 etc. (VAZ, 2004); o segundo estudo aborda o Museu Oscar Niemeyer e seu público, em que parte das discussões apresentadas mensura a representatividade desse espaço cultural no campo artístico em função da constituição do seu acervo e das exposições promovidas. Nesse caso, a pesquisa teve como recorte temporal o período de 2003 a 2011 (VAZ, 2011). Além disso, para analisar o repertório imagético produzido pelas artistas locais, adotam-se como fontes as obras de arte disponibilizadas on-line pela Enciclopédia Itaú Cultural e SEEC. 
Portanto, considerando as diferentes posições percorridas no campo artístico pelas artistas mulheres entre 2000 a 2011, indaga-se: Dada as exposições em espaços comerciais e intermediários, elas tiveram alguma repercussão no acervo permanente do museu ou não? O que explica a presença de algumas das artistas nos espaços oficiais e intermediários?

\section{Artistas mulheres e espaços em disputa}

A disputa por espaço no campo artístico em Curitiba permite compreender que esse âmbito social está ligado a outras esferas de poder; a arte como dimensão política e social coloca em xeque a ideia de dom artístico, visto que o indivíduo está atrelado à sociedade, e suas ações marcam posições ao longo de suas trajetórias, ou seja, as escolhas dos artistas, homens e mulheres, tanto pessoais quanto profissionais interferem na obra plástica produzida e na sua valorização pelo sistema de arte.

Toda trajetória social deve ser compreendida como uma maneira singular de percorrer o espaço social, onde se exprimem as disposições do habitus; cada deslocamento para uma nova posição, enquanto implica a exclusão de um conjunto mais ou menos vasto de posições substituíveis e, com isso, um fechamento irreversível do leque de posições inicialmente compatíveis, [...]. (BOURDIEU, 1996, p. 292)

A trajetória desenvolve-se no espaço social de modo relacional. No recorte proposto, parte da trajetória de cada grupo de artistas mulheres foi delineada pela produção vinculada à galeria, e suas posições no campo artístico ponderadas pelo reconhecimento comercial e simbólico; dessa forma, cada subgrupo de artistas ligado às galerias tem suas posições artísticas entrelaçadas pela participação no Catálogo Julio Louzada como atributo comercial da obra, somado à aceitação das obras no Salão Paranaense e premiações correspondentes como valor simbólico (VAZ, 2004).

Além do valor comercial e simbólico de cada artista mapeada pelo estudo das galerias, adota-se o acervo do MON como outro fator comparativo para verificar se a produção das mulheres atuantes nas galerias de artes ativas no período de 2000 a 2003 
também tinham uma representatividade oficial, percurso que individualiza cada trajetória em função das posições ocupadas nos termos de Bourdieu (1996).

A posição da artista envolve o diálogo e a cumplicidade com os "legitimadores da arte" que, por extensão, tem sua representatividade posta à prova, frente a reconversões necessárias para se manter numa posição de vanguarda. Quando a produção de artistas mulheres se pauta na arte feminista, a conversação ou troca de dons as coloca numa posição contraditória e retrata a violência simbólica a qual elas estão sujeitas, nos termos de Bourdieu (2009). Visto que,

[...] as artistas feministas, enquanto protagonistas de um campo que as legitima mas que também as subordina, ocupam uma posição contraditória porque criticam um sistema no qual pretendem obter legitimação, alcançar capital económico e ter posse de poder. Buscam, por um lado, reconhecimento do campo e das instituições que o compõem e, por outro, criticam o próprio funcionamento dessas instituições não deixando de quererem ser incluídas. Não obstante a aparente contradição, a posse de poder por parte das feministas faz sentido porque lhes permite a obtenção de capacidade de remover ou promover legitimação. (FONSECA, 2013b, p. 131)

A adequação do habitus e a compreensão de que os valores e estilos de vida das artistas mulheres com produção feminista estão em consonância com os mediadores culturais, são fatores condicionantes para inserção dessas no mundo da arte. Universo esse dominado por homens, os quais têm função de atestar as produções artísticas que serão aceitas como legítimas.

Para Fonseca (2013b), participar do circuito acarreta vantagens e desvantagens para as artistas feministas. O fator positivo é a visibilidade e a representatividade de sua arte pela ampliação do público e das instituições, nas quais estão vinculadas a sua produção, bem como, a possibilidade de colocar em pauta questões sociais de diferentes ordens. O fator negativo refere-se à imagem da obra legitimada, cujos julgamentos mostram um olhar idealizado e generalista sobre a produção feminista e suas carreiras artísticas.

As diferentes posições ocupadas pela artista no campo da arte dependem do capital acumulado ao longo de sua trajetória. Dentre os capitais acumulados pelos grupos 
de mulheres que seguiram a carreira artística em Curitiba, tece-se o valor comercial, simbólico e oficial; posições atribuídas a partir de uma mesma unidade temporal e espaço geográfico, cuja diferença entre os grupos se pauta no "lugar" onde suas obras estavam expostas. Locais delineados a seguir, que apresentam a quantidade de artistas e obras que compõem o mercado comercial, simbólico e oficial em Curitiba no período citado.

Neste artigo, para apresentar os caminhos possíveis do sistema de arte em Curitiba, primeiramente sobre a produção comercial, apresentam-se as galerias de arte ativas no período de 2000 a 2003, seguindo a tipologia: comerciais ${ }^{1}$ e intermediárias ${ }^{2}$. As 13 galerias de artes mapeadas apresentam uma realidade empírica específica a março de 2004, o que resultou na classificação: comercial, intermediária e de vanguarda, data em que foi realizada a pesquisa de campo. Portanto, não englobava todas as galerias existentes em Curitiba no início do século XXI, e a classificação desses espaços foi realizada com base em seis critérios: 1) maneira de expor as obras, 2) existência de etiquetas de preço, 3) realização de exposições artísticas, 4) existência de artistas falecidos no grupo de artistas representados pela galeria, 5) adequação do espaço arquitetônico e modo de conservação das obras, 6) localização geográfica nos bairros de Curitiba (VAZ, 2004). Por exemplo, as galerias de vanguarda (Casa da Imagem e Ybakatu) realizavam exposições de artistas e não tinham etiquetas de preço em suas obras quando expostas ao público.

$\mathrm{Na}$ sequência, mapeia-se numericamente quantos artistas compõem esse subgrupo, dividido em artistas homens e artistas mulheres, conforme cada categoria de galeria (Quadro 1). E contabiliza-se também a quantidade de obras comercializadas por artista. As galerias comerciais totalizam 71 artistas e 337 obras, das quais se têm: 46 artistas homens (239 obras) para 25 artistas mulheres (98 obras). Detalhando os artistas e as obras das galerias intermediárias, elencam-se 42 artistas e 197 obras; desses, 27 artistas são homens (144 obras) e 15 artistas são mulheres (53 obras). Na galeria de vanguarda tem-se quatro artistas, duas mulheres e dois homens.

\footnotetext{
${ }^{1}$ Antichità, Um Lugar ao Sol, Nini Barontini, PallLajos e Schneider (VAZ, 2004).

${ }^{2}$ Fratelli Rubbo, Acaiaca, Noris Espaço de Arte, Galeria Simões de Assis, Solar do Rosário e Manolo Saez (VAZ, 2004).
} 
Quadro 1 - Quantidade de artistas e obras: mercado comercial, simbólico e oficial, Curitiba/PR (2000-2011)

\begin{tabular}{|c|c|c|c|c|}
\hline ESPAÇOS & $\begin{array}{l}\text { N. ARTISTAS } \\
\text { HOMENS }\end{array}$ & $\begin{array}{l}\text { N. ARTISTAS } \\
\text { MULHERES }\end{array}$ & $\begin{array}{c}\text { N. DE OBRAS } \\
\text { ARTISTAS } \\
\text { HOMENS }\end{array}$ & $\begin{array}{c}\text { N. DE OBRAS } \\
\text { ARTISTAS } \\
\text { MULHERES }\end{array}$ \\
\hline $\begin{array}{l}\text { Galeria } \\
\text { comercial }\end{array}$ & 46 & 25 & 239 & 98 \\
\hline $\begin{array}{l}\text { Galeria } \\
\text { intermediária }\end{array}$ & 27 & 15 & 144 & 53 \\
\hline Parcial 1 & 73 & 40 & 383 & 151 \\
\hline $\begin{array}{l}\text { Galeria de } \\
\text { vanguarda }\end{array}$ & 2 & 2 & 3 & 3 \\
\hline $\begin{array}{l}\text { Exposiçõos de } \\
\text { vanguarda }\end{array}$ & 18 & 22 & - & - \\
\hline Parcial 2 & 20 & 24 & 3 & 3 \\
\hline Acervo MON & 69 & 20 & 266 & 386 \\
\hline Total & 162 & 84 & 652 & 540 \\
\hline
\end{tabular}

Fonte: Vaz $(2004,2011)$.

Excetuando a produção de vanguarda, referente a Ybakatu Espaço de Arte e a Casa da Imagem, tanto nas comerciais, quanto nas intermediárias, prevalece em quantidade a produção de artistas homens, assim como o número de obras comercializadas também é superior se comparada à produção de artistas mulheres - as produções no espaço simbólico e oficial serão delineadas posteriormente.

Ainda sobre o espaço comercial, o quadro 2 nomina quem são as artistas mulheres que conquistam o mercado comercial, e permite avaliar a divisão de status dentro do grupo, ou seja, de 37 artistas, tem-se 22 com obras comercializadas nas galerias comerciais, totalizando 87 obras, e 12 artistas com obras vinculadas nas galerias intermediárias, somando 32 obras, e ainda, nas duas modalidades de galerias, tem-se três artistas: Corina Ferraz, Miriam Martins e Vivian Vidal, perfazendo o total de 32 obras. Nota-se que as galerias intermediárias têm menos artistas e obras o que, em hipótese, enfraquece as expectativas do subgrupo comercial atingir o reconhecimento oficial. 
Quadro 2 - Artistas mulheres: mercado comercial, Curitiba/PR (2000-2003)

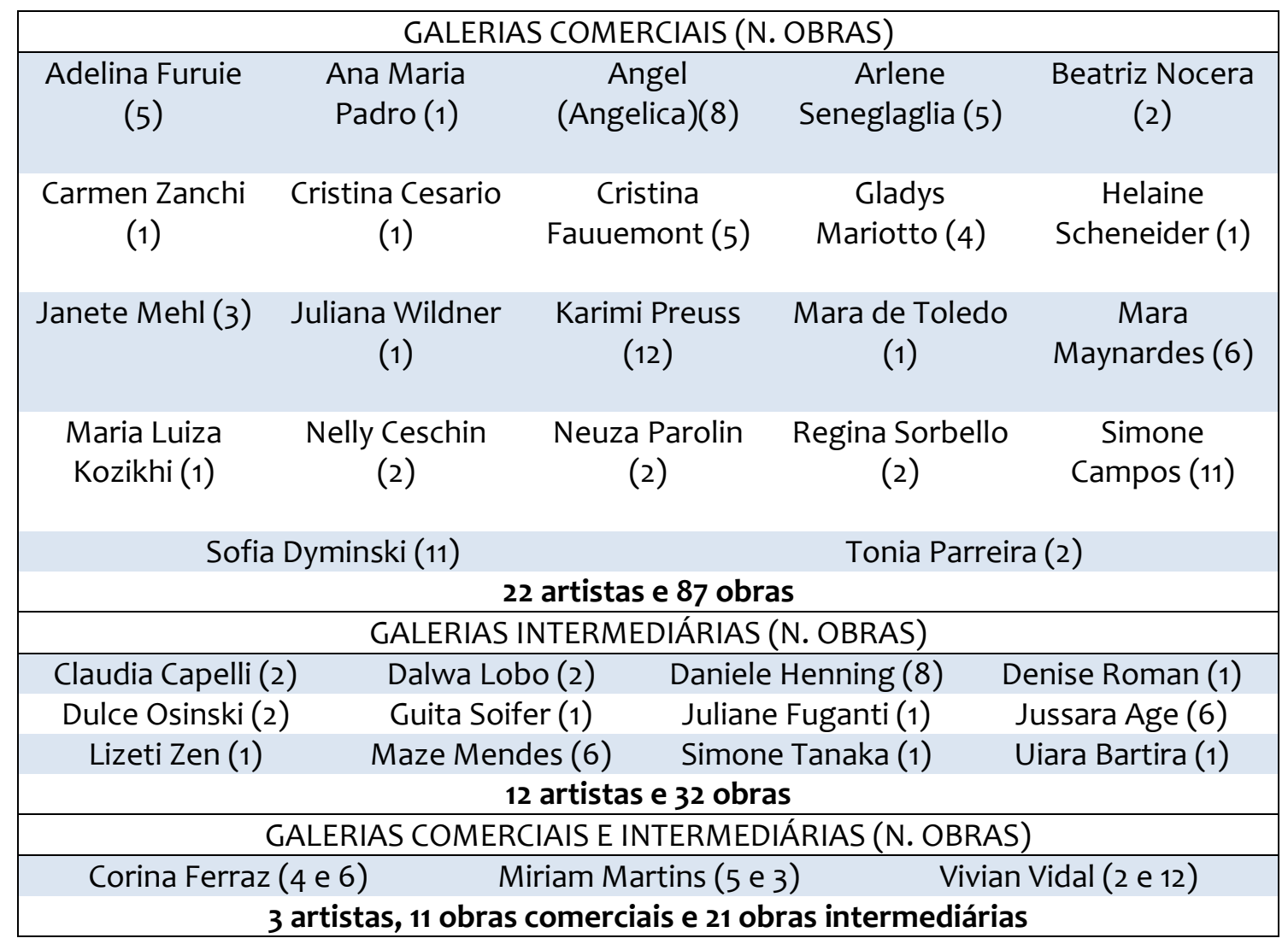

Fonte: $\operatorname{Vaz}(2004)$.

A redução do número de artistas será comprovada como verdadeira na análise desenvolvida na sequência, tanto na transição do mercado comercial para o simbólico, quanto do mercado simbólico para o oficial, o que corrobora as colocações de Fonseca (2013b) sobre a dimensão econômica do circuito artístico e a posição da arte produzida pela mulher nesse meio social, visto que o peso do mercado primário não é o mesmo que do mercado secundário. Sendo assim, a aceitação da produção de artistas mulheres oficializadas por suas obras integrarem acervos de museus de grande porte, coloca-se como uma posição restrita no campo da arte, que se pode visualizar pela imagem de uma pirâmide nos termos de Fonseca (2013b), em que o valor de cada artista é medido pela distância simbólica e pelo "capital agregado" ao longo da escalada ao cume da pirâmide, entre os espaços de menor e maior prestígio, respectivamente.

Capital que classifica desde os artistas menos valorizados até os mais prestigiosos, ethos profissional que faz do artista um ser individualista, carismático e empreendedor, em que suas ações ocultam as necessidades econômicas e suas trajetórias de vidas, dessa 
forma atendem a regras e condições extra artísticas do circuito comercial. A vida do artista começa com sua inserção no campo artístico por meio de um apagamento de suas origens, laços sociais e sua subjetividade, com forte acento em sua expressividade nos termos da "arte pela arte".

Um segundo ponto da trajetória refere-se à produção simbólica que abrange as obras expostas na galeria de vanguarda e a participação das artistas nas mostras de vanguarda realizadas no período de 2000 a 2002, na compreensão que,

[...] a noção de campo, definida em conformidade com a realização de um estudo empírico concreto, necessita ser compreendida em sua interdependência, ou seja, em relação a outra(s) noção(ões) - por exemplo, as noções de campo, habitus e capital não podem ser definidas isoladamente, mas apenas no interior de um sistema teórico que constituem. (CATANI, 2011, p. 191, grifo do autor)

Logo, as posições ocupadas pelas artistas mulheres no campo não são fixas, dependem do habitus e dos capitais acumulados, cujas lutas internas entre os agentes e os espaços sociais em que transitam interferem na conservação, ou não, de posições já adquiridas, uma vez que a realidade empírica é historicamente situada e datada.

Neste artigo é em função da participação nas três exposições de vanguardas que se mensura o valor simbólico das artistas, grupo representado por 40 entre homens e mulheres - já que uma parcela dos nomes se repete por participar em duas ou três das mostras listadas - tanto que, no conjunto, houve a presença de 22 artistas mulheres (VAZ, 2004). Isolando cada exposição, havia 12 artistas na FCC (8 homens e 4 mulheres); 10 artistas na Síntese do Paraná (6 homens e 4 mulheres); 30 artistas na Faxinal das Artes (12 homens e 18 mulheres). Dentre elas, Carina Weidle, Laura Miranda, Maria Cheung participaram de duas exposições, e Dulce Osinski expôs sua obra em três eventos.

Na primeira mostra, elencam-se os artistas que participaram da exposição da FCC em 2000, os quais representaram a produção de arte contemporânea no Paraná, incluindo as artistas que ingressaram no campo da arte via Salão Paranaense na década de 1980 e 1990 O objetivo do evento, na data em questão, era selecionar obras para compor o acervo permanente do Museu Metropolitano de Arte de Curitiba e do Museu 
da Gravura Cidade de Curitiba. A exposição totalizou 12 artistas paranaenses e 94 obras, e, como representantes da produção feminina, tem-se: Carina Weidle, Dulce Osinski, Eliane Prolik e Laura Miranda (VAZ, 2004). Os curadores da mostra eram Alberto Puppi, Paulo Reis, Simone Landal e Adriana Berbeka. No caso das artistas mulheres, Weidle e Prolik possuem vínculo com a Galeria Casa da Imagem, considerada de vanguarda no mercado local, espaço que surge no início da década de 1990. Alusivo às outras galerias, as obras de Osinski eram comercializadas na Noris Espaço de Artes (grupo intermediário).

A segunda exposição: "Síntese do Paraná: Arte Atual”, foi realizada na Casa Andrade Muricy, tendo como organizador Ennio Marques Ferreira, e apresentava dez artistas com curadoria de dez profissionais da área, respectivamente. Do total de profissionais envolvidos, tem-se a mesma proporção entre homens e mulheres, além dos nomes das artistas já citados pela mostra realizada na FCC (Weidle e Osinski), e a participação de mais sete mulheres: de um lado, assumindo a posição de artistas (Juliane Fuganti e Maria Cheung) e, de outro, na posição de curadoras (Tania Bloomfield, Maria J. Justino, Maria Cecilia A. de Noronha, Adalice M. de Araujo e Nilza N. Procopiak) -; Fuganti tinha suas obras expostas nas galerias intermediárias.

O evento "Faxinal das Artes", terceira mostra, selecionou 100 artistas de todo Brasil e tinha como objetivo conjugar um programa de residência artística com a constituição de um acervo de arte contemporânea. Do total de artistas brasileiros, 30 eram do Paraná: 12 artistas homens e 18 artistas mulheres (VAZ, 2004), sendo que, entre os homens, Edilson Viriato, Fabio Noronha tinham vínculo com as três mostras, assim como Jose A. de Lima, Luiz C. Brugnera, Marlon de Azambuja e Rogerio participaram em duas delas. Do grupo de mulheres, executando as exposições da FCC e da Síntese do Paraná, igualmente integraram o campo: Alice Yamamura, Ana Gonzales, Bernadete Amorim, Conceição Rodriguez, Debora Santiago, Deise Marin, Didonet Thomaz, Gleyce Cruz, Guita Soifer, Leila Pugnaloni, Leticia Faria, Maines Olivetti, Marga Puntel, Maze Mendes, Rossana Guimarães e Tania Bloomfield - embora, Bloomfield tenha assumido a curadoria na mostra organizada por Ennio M. Ferreira.

Por fim, o terceiro ponto de análise da trajetória das artistas refere-se a mulheres que compõem o acervo do MON cujas obras são classificadas em locais, nacionais e internacionais. Do total de 89 artistas, temos: 34 locais, 41 nacionais e 14 internacionais 
(VAZ, 2011). Com base nessa primeira classificação, subdividiu-se em artistas homens e artistas mulheres para cada categoria, observando-se que a produção local se divide em 23 homens ( 87 obras) para 11 mulheres ( 272 obras), ver quadro 3.

Quadro 3- Quantidade de artistas e obras: acervo MON, Curitiba/PR (2003-2011)

\begin{tabular}{|l|cc|cc|}
\hline \multirow{2}{*}{ EXPOSIÇÕES } & \multicolumn{2}{|c|}{ N. ARTISTAS } & \multicolumn{2}{c|}{ N. OBRAS } \\
\cline { 2 - 5 } & HOMENS & MULHERES & HOMENS & MULHERES \\
\cline { 1 - 1 } Locais & 23 & 11 & 87 & 272 \\
\cline { 1 - 1 } Nacionais & 34 & 7 & 143 & 104 \\
\cline { 1 - 1 } Internacionais & 12 & 2 & 36 & 10 \\
\cline { 1 - 1 } Total & $\mathbf{6 9}$ & $\mathbf{2 0}$ & $\mathbf{2 6 6}$ & $\mathbf{3 8 6}$ \\
\hline
\end{tabular}

Fonte: Vaz (2011, p. 375-377).

O número maior de obras de artistas mulheres justifica-se pela produção de quatro artistas: Uiara Bartira, que totaliza 225 obras na linguagem de gravura incorporada ao MON em 2008; Rossini Perez, com 55 obras em gravura, cuja produção integra parte do acervo do museu a partir de 2010; a artista nacional Maria Bonomi, que possui 37 obras no acervo, das quais 30 objetos são incorporados em 2008; Dulce Osinski, com 23 obras - 20 na linguagem de pintura e três na linguagem de desenho, com entrada no acervo em 2008. Em quantidade, as demais obras variam de uma a nove unidades por artista, independentemente da localidade (VAZ, 2011). Na produção nacional e internacional também prevalece a produção de artistas homens: nacionalmente, temos 34 artistas (143 obras) para 7 artistas mulheres (104 obras); internacionalmente, somam 12 artistas homens com 36 obras para 2 artistas mulheres com 10 obras.

Como síntese da participação das artistas mulheres com obras vinculadas no mercado simbólico e oficial, considerando a produção local, tem-se o total de 33 mulheres (Quadro 4). Constata-se que Osinski integra tanto o mercado comercial (galerias intermediárias), quanto o simbólico (exposições de vanguarda) e oficial (acervo MON). 
Quadro 4 - Artistas mulheres: mercado simbólico e oficial, Curitiba/PR (2000-2011)

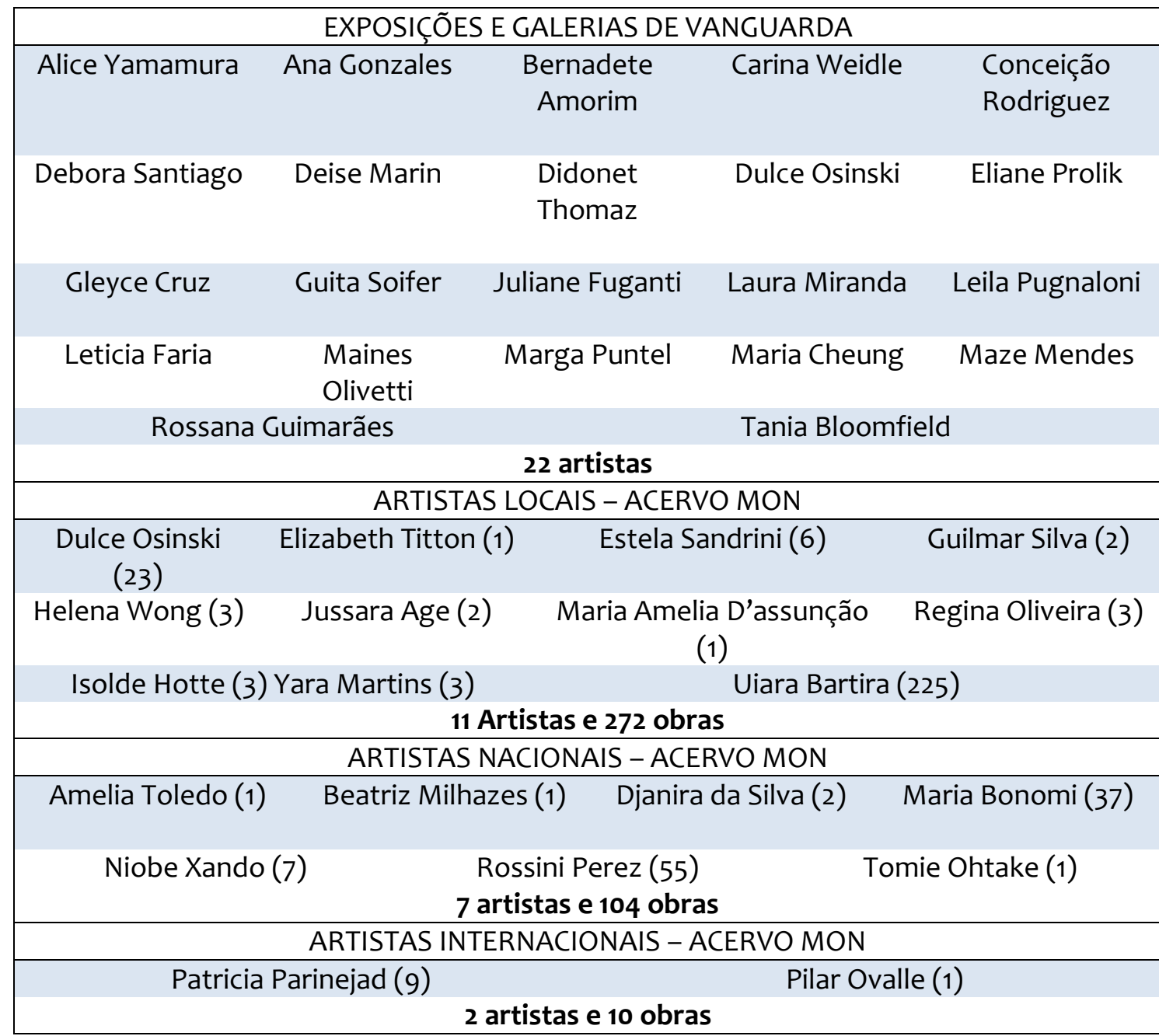

Fonte: Vaz (2004 e 2011).

Reitera-se que as três exposições de vanguardas analisadas no estudo das galerias de arte foram escolhidas em função de serem eventos promovidos por instâncias oficiais do estado do Paraná e da prefeitura de Curitiba, na época sendo também uma maneira de constituição dos acervos artísticos de diferentes instâncias museológicas. Em particular, no estudo das galerias de arte, uma das hipóteses comprovada é que os artistas com participação nas galerias comerciais e intermediárias, em particular os do subgrupo comercial, tinham menor probabilidade de conservar suas posições de vanguardas.

Esse espaço de lutas configura o campo artístico, cujas regras se pautam na polaridade entre o mercado comercial e simbólico. O artista e sua obra são reconhecidos pelo seu valor simbólico, critério de julgamento adotado por instâncias oficiais como o MON, que ao comporem seus acervos, escolhem artistas que assumiram posições de 
vanguarda do campo artístico. Embora ter conquistado capital simbólico não isente o artista de ocupar, em determinados momentos de suas trajetórias, outros espaços, e de transitarem em galerias do mercado comercial, o que explica os espaços intermediários agregarem artistas dos dois polos: das galerias comerciais e das exposições de vanguarda.

Em suma, das 22 artistas mulheres que integram o mercado comercial e que expuseram exclusivamente em galerias comerciais (Quadro 2), observa-se que elas não tiveram suas obras aceitas pelo MON, ou seja, o mercado simbólico e oficial marca posições específicas de cada agente no campo (Quadro 4). Igualmente, constata-se que aquelas que representam cada subgrupo no campo da arte, dividido em espaços comerciais e simbólicos, sem incluir o acervo do MON, é menor a cada patamar que sobem rumo ao cume da pirâmide. Do total de 37 artistas mulheres que fazem parte do mercado comercial, apenas seis conservam suas posições de vanguarda e ascendem ao mercado simbólico: Dulce Osinski, Guita Soifer, Juliane Fuganti, Jussara Age, Maze Mendes e Uiara Bartira.

Ao confrontar as instâncias de valorização comercial, simbólica e oficial, nota-se que no mercado mediado pelas galerias comerciais e no mercado oficial, mapeado pelo acervo do MON, a produção masculina é maior em comparação à feminina. No caso da produção oficial, considerando o quesito abrangência geográfica, vê-se que a produção de artistas mulheres é mais restritiva pela relevância internacional no MON. Do total de 14 artistas (100\%) que fazem parte do acervo do museu, apenas 2 (14,2 \%) são mulheres. Quanto ao mercado simbólico em Curitiba, mediado pelas galerias de vanguarda e pelas exposições realizadas pela FCC e SEEC, o número de artistas mulheres é superior ao de homens, situação que se inverte quando se avalia o espaço oficial do museu; do total de 34 artistas locais (100\%), tem-se 11 mulheres (32,3\%). São elas: Dulce Osinski, Elizabeth Titton, Estela Sandrini, Guilmar Silva, Helena Wong, Isolde Hotte, Jussara Age, Maria A. D’assunção, Regina Oliveira, Uiara Bartira e Yara Martins. Desse grupo, Osinski, Age e Bartira comercializam suas obras nas galerias intermediárias. Osinski participa também do mercado simbólico. Partindo da produção aceita oficialmente pelo MON, com base na produção local, questiona-se: O trabalho delas está voltado ou não para questões feministas? 
[...] o corpo sob a marca da raça no ensino artístico brasileiro oitocentista era ainda tabu.

É possível localizar ainda, na AIBA, um outro tabu. É o do estudo a partir do modelo vivo feminino que durante todo século XIX não foi permitido. Com isso, os estudos de corpos femininos só foram executados diante de estátuas de gesso ou a partir de cópias de estampas e gravuras.

$[\ldots]$

um modelo vivo feminino em sala de aula no século XIX significaria a presença efetiva de uma mulher num circuito estritamente masculino. A instituição oficial de arte - e ensino de arte - era um lugar apenas para homens, valores, crenças e conceitos comuns ao universo artístico masculinizado de então. (BATISTA, 2011, p. 162-164)

Por um aspecto anacrônico, nos trechos anteriores, constata-se que entre os anos de 1860 a 1890, considerando as mais de 60 academias observadas por Stephanie Batista (2011), no Museu Dom João VI, e das dez academias no Museu Nacional de Belas Arte, o corpo negro e o modelo feminino eram tabus no ensino promovido pela Academia Imperial de Belas Artes (AIBA) do Rio de Janeiro. Ainda sobre a produção artística no final século XIX, a pintura de Almeida Junior, O Descanso do Modelo (1882), exposta na Exposição Geral de 1884, tematiza a forma de trabalho entre artistas homens e modelos mulheres em ateliê privado. Essa pintura revela uma hierarquia entre homens e mulheres, "reforça o olhar voyeur tal como ele é estabelecido na convencional matriz heterossexual, o sujeito masculino e o objeto de observação feminino." (BATISTA, 2011, p. 233).

Seguindo as colocações de Fonseca (2013b), diferentes papéis, para homens e mulheres, igualmente marcam o campo da arte em seus aspectos econômicos. A mulher, ao ascender em postos de decisão no campo da arte, consegue romper com a dominação masculina. Visto que, segundo Fonseca (2013a), houve avanço da produção feminista em função de artistas mulheres que passam a participar do mercado de bens simbólicos na última década em Portugal. Porém, em outro estudo, mesmo com o aumento da participação de artistas mulheres em Portugal a partir desse novo milênio, o autor revela que as produções feministas são ínfimas nas carreiras artísticas em posições de topo do campo artístico, situação decorrente de vários fatores interligados. Um deles é que os 
grandes compradores que operam nos leilões de arte, e mesmo os legitimadores culturais que detêm capital simbólico e atuam nos amplos circuitos museológicos e culturais, são homens.

Na visão masculina, o objeto artístico é uma mercadoria e, em seu aspecto econômico, a arte é vista como investimento independente dos seus conteúdos. A diferença de obras feitas por homens e mulheres é mensurada pela cotação do mercado em dólares.

Enquanto a obra mais cara (até 2008) feita por uma mulher, a 'Spider', de Louise Bourgeois, atinge os 10,7 milhões de dólares; o 'Portrait of Joseph Roulin', de Vincent van Gogh, posicionado no $10^{\circ}$ posto das obras mais caras (até 2008), atinge os 58 milhões de dólares. (FONSECA, 2013b, p. 129 , grifo do autor)

Tendo em vista que a valorização das obras no campo da arte varia de acordo com o gênero, fator de desigualdade e discriminação, já que existe uma assimetria generalizada entre a consagração entre homens e mulheres artistas. Independente dos avanços sentidos a partir da arte moderna, quando comparado ao período clássico da história da arte, em que as mulheres eram "aceitas" como tema para os nus artísticos no sentido contemplativo, nota-se que o campo artístico ainda assim é sexista.

[...] os preços das obras de mulheres permanecem muito mais baixos comparados com as dos homens, o que significa que são mais mal pagas e que têm menos oportunidades de desenvolver trabalho artístico, quando comparadas com os pares do outro sexo. O cerco fica ainda mais apertado quando se trata de arte feminista. (FONSECA, 2013b, p. 130)

Então, no aspecto comercial, as obras têm baixa cotação de venda e, no aspecto simbólico, a imagem da mulher é associada ao deleite estético, não como produtora que defende a igualdade de gênero por meio de obras feministas.

Luciana Loponte menciona que a imagem da mulher no universo artístico é apreciada em função de uma análise formalista, em que "o modelo aceito como verdadeiro" não potencializa interpretações que problematizem as relações de poder, gênero e sexualidade, marcas do campo da arte. A sexualidade da mulher, comunicada 
pelas imagens produzidas por homens e mulheres no decorrer da história da arte, resulta no que a autora denomina de "pedagogia do feminino". Segundo Loponte (2002, p. 283284): "uma pedagogia visual que naturaliza e legitima o corpo feminino como objeto de contemplação, tornando esse modo de ver particular como a única ‘verdade’ possível”. Fato que parte do "olhar masculino", em que a mulher é passiva e submissa; sua imagem retratada na obra de arte está endereçada a uma plateia também dominada por homens.

No caso das mulheres artistas, elas são sempre apêndices de alguém: filha de, esposa ou amante de, mãe de... Elas e suas realizações precisam ser justificadas a partir da sua relação com outros. Como crianças que precisam ser conduzidas, as mulheres artistas e suas produções são sempre colocadas à prova, e sua capacidade de criação além dos limites da maternidade e reprodução é regularmente questionada, legitimando a arte como produto da criatividade e da genialidade masculinas. (LOPONTE, 2002, p. 288)

A mudança desse cenário vislumbra a implementação de políticas focadas na igualdade de gênero, que possibilitem às mulheres desenvolverem suas carreiras artísticas e que, consequentemente, aumentem as possibilidades de consagração da produção feminista. Além disso, que mulheres ou homens, que defendem uma arte feminista, venham a ocupar cargos de decisões no campo da arte e atuem como agentes ativos nos espaços culturais e escolares, ampliando as estratégias de acesso e permanência dessas produções no mercado de bens simbólicos. Esse é o caso das pesquisas de Valdoni R. Batista, Margarida G. Rauen (2017) e Doacir D. Filho (2018), que tematizam sobre o antropocentrismo, a discriminação interseccional e a pouca representatividade de artistas mulheres no currículo do ensino superior e nos conteúdos de livros didáticos de arte no Paraná.

O problema de política cultural também é sinalizado por Ana Mae Barbosa, no texto apresentado na Associação Nacional de Pesquisadores em Artes Plásticas. Uma de suas críticas aborda a "Mostra do Redescobrimento", apresentada no Parque IbirapueraSP em 2000. A exposição não tinha nenhuma obra de artista mulher, pois, 
[...] a prova é que o curador do segmento, [...], obediente a uma história da Arte etnocêntrica e excludente, não apresentou nenhuma obra de artista mulher, quando não precisava se aprofundar muito em pesquisas para descobrir não só Maria Pardos, Alice Santiago e mais umas 200 mulheres listadas numa obra esgotada a cinquenta anos de Theodoro Braga, [...]. (BARBOSA, 2010, p. 1980)

Barbosa posiciona-se a respeito da carência de respaldo institucional na promoção de exposições que versem sobre artistas mulheres e critica o número reduzido de obras disponíveis em diferentes instituições culturais, que identifiquem a produção realizada por elas. Esses fatores contribuem para que as produções das artistas se tornem invisíveis e insignificantes, complicando seu reconhecimento no meio artístico brasileiro. Dificuldade que resulta no apagamento da história das artistas mulheres pelas intuições promotoras de arte, na omissão de se posicionarem de forma crítica frente a questões de gênero, e na mudança da própria produção que se ajusta a uma arte feita por mulheres.

Ao se referir às obras de Anita Malfatti (1889-1964) e Tarsila do Amaral (1886-1973), a autora comenta que o mais grave no caso de artistas mulheres que não caíram no esquecimento, é que a memória é mensurada pela sua posição como mulheres/amantes e não como artistas produtoras de arte.

Em continuidade, à apreciação de parte das obras das artistas locais com reconhecimento oficial adota-se como hipótese que o repertório imagético, produzido ao longo de suas trajetórias, segue o padrão visual apresentado por Loponte, caracterizado por análises de cunho formal relacionadas às suas produções, com imagens que atendem ao estilo figurativo e abstrato, cujas temáticas não problematizam as questões de gênero. Para tanto, divide-se a abordagem em duas partes: na primeira, as mulheres que em sua trajetória têm vínculo mercadológico e simbólico com as galerias e exposições de arte já citadas; na segunda, as mulheres cuja representatividade é validada pelo acervo do MON.

Como parâmetro simbólico e ponto de destaque no caminho trilhado pelo primeiro subgrupo de mulheres, analisa-se a participação e premiação no Salão Paranaense, com base nos eventos realizados entre 1944 e 2003 (VAZ, 2004). Como artistas representantes da década de 1980, já que as primeiras participações no Salão são predominantemente nesse período, tem-se: Dulce Osinski (OSINSKI, 2021) - nascida em 
1962, em Irati-PR -, teve sua entrada no mercado simbólico no ano de 1984; foi premiada nesse mesmo certame artístico no ano de 19903; Jussara Age4 (nascida em 1953), cujo vínculo com o Salão se efetiva na transição entre a década de 1970 e 1980, perfazendo duas participações: a primeira em 1977 e a segunda em 1983, data em que obteve premiação; Uiara Bartira - nascida em 1949, em Curitiba-PR -, também com duas participações no Salão (1981 e 1983), sendo premiada no mesmo ano em que Jussara Age (AGE, 2021). Bartira tem sua trajetória acadêmica iniciada com o curso de pintura na Escola de Música e Belas Artes do Paraná (1977) e prossegue com a realização do mestrado (entre 1989 e 1992) e a defesa do doutorado em 2007 (BARTIRA, 2021).

Quanto às exposições realizadas por essas três artistas, e o perfil imagético de suas obras, constata-se que seus caminhos estão interligados em função de suas participações em eventos de arte coletivos no transcorrer da década de 1980. Em 1984, Jussara Age e Uiara Bartira participam da mostra "Valores atuais do Paraná", composta por 11 artistas selecionados no $40^{\circ}$ Salão Paranaense, realizada em parceria com diferentes instituições educacionais e culturais, como a Prefeitura Municipal de Maringá (Galeria de Artes - Biblioteca Municipal de Maringá); o MEC/ FUNARTE (Galeria Macunaíma, Rio de Janeiro); a Prefeitura Municipal de Londrina (Sala Celso Garcia Cid, Londrina); etc.

Em 1990, Osinski realiza a exposição individual "Retratos de Família” na Sala Theodoro de Bona - MAC/PR; no mesmo ano, participa da coletiva denominada Mostra Anual de Gravura da Cidade de Curitiba - esses são alguns eventos divulgados pela Enciclopédia sobre o seu vínculo com o campo da arte. Das suas pinturas, destacam-se duas, de 1989: A Juventude das Tias Rosa e Hela e Dulcinha com seus pais (OSINSKI, 2021).

No segundo subgrupo, as artistas têm seu reconhecimento nos certames artísticos locais em décadas distintas. Entre o final do século XIX e as primeiras décadas do século

\footnotetext{
${ }^{3}$ A obra O segundo guardião dos anjos, feita em óleo sobre tela, medindo 100 x 99,9 cm, recebeu o Prêmio Museu de Arte Contemporânea do Paraná.

4 Uma obra "abstrata" na técnica litografia e pertencente acervo do Banco Itaú é divulgada pela Enciclopédia. Sua entrada no campo artístico é sinalizada pelas exposições: Mostra da Gravura da Cidade de Curitiba (1984 e 1986); Tradição/Contradição, Curitiba/PR (1986); Semana da Gravura, Santa Maria/RS (1987). (AGE, 2021).

${ }^{5}$ A pesquisa de mestrado: A Evolução da estética da gravura brasileira, sob a orientação de Maria Bonomi; e de doutorado: Arte-Decodificação cosmológica, sob a orientação de Paulo Herkenhoff.
} 
XX, têm-se: Isolde Hotte (1902-1994), ceramista natural de Curitiba; Maria A. D’assunção (1879-1955), artista de Joinville-SC. Pela Enciclopédia, não se tem referência ao perfil imagético de seus trabalhos artísticos, cujas conexões artísticas remetem aos ensinamentos de Alfredo Andersen (D’ASSUNÇÃO, 2021).

Luis Salturi (2011, p. 56) menciona que Andersen é considerado por muitos autores como o "Pai da Pintura Paranaense", devido ao trabalho pioneiro que desenvolveu na formação de vários artistas. Dentre as mulheres estavam Maria A. D’Assumpção, Isolde Hotte, Silvina Bertagnoli, Inocencia Falce, Lidia De Marco, Sinhazinha Rebello. Sobre a posição e a temática da produção de artistas mulheres no universo artístico, o autor complementa:

[...] ainda que no Paraná do início do século XX as mulheres fossem aceitas como alunas das escolas e dos ateliês sem qualquer restrição explícita, é preciso destacar que o ofício artístico era entendido como um refinamento do trabalho doméstico ou do magistério, pois a carreira de artista plástico era pensada como uma profissão masculina. Contudo, muitas mulheres que foram alunas de Alfredo Andersen vieram a se destacar como pintoras [...]. Embora algumas dessas artistas tenham também produzido paisagens, a maior parte de suas produções é composta por flores, naturezas-mortas e retratos, gêneros considerados 'menores' naquele contexto. (SALTURI, 2011, p. 114)

Maria Amelia tem suas obras vinculadas a exposições realizadas em 1986 (Tradição/Contradição, Curitiba), 1991 (Museu Municipal de Arte - Acervo 1991, Curitiba) e 2004 (A paisagem paranaense e seus pintores), o que sinaliza que seu reconhecimento na arte ocorreu tardiamente, pois em 1944 participou da "Exposição de arte paranaense no Rio", organizada pela Sociedade Amigos de Alfredo Andersen, coletiva que contou com a produção de 29 artistas, no total de 124 obras. Estão incluídas: Inocencia Falce (1), Isolde Hotte (1), Jeanette Gabordi (1), Leonor Boterri (1), Maria Amelia D’Assumpção (2) e o número dos respectivos objetos artísticos expostos (SALTURI, 2011, p. 105).

O reconhecimento tímido e tardio igualmente ocorreu com Isolde Hotte (19021994) ${ }^{7}$, pintora e ceramista paranaense ${ }^{8}$ (DEL VECCHIO, 2010, p.1). Na Enciclopédia, sua

\footnotetext{
${ }^{6}$ Questão abordada por Michele A. Fanini (2009).

7 Outro evento destacado por Salturi (2011, p. 102) trata da "Primeira Exposição da Sociedade Amigos de Alfredo Andersen” realizada em 1941, no qual elenca-se a produção de: Iria Correia (1 desenho), Helena Dais (1 pintura), Inocencia Falce (3 pinturas), Isolde Hotte (2 pinturas) e Nadir Costa (1 pintura).
} 
produção é referenciada como artista convidada na mostra coletiva "Salão Nacional de Cerâmica" (2010), evento realizado pela Casa Andrade Muricy com curadoria de Richard Bischof, Roseli Fischer Bassler e Soraia Savaris (HOTTE, 2021); e na mostra "Isolde Hotte, e sua obra", realizada no MON (2014). Fernando Bini curador dessa exposição no MON menciona: "o importante nesta exposição é o ressurgimento de uma obra plástica excepcional que foi feita aqui no Paraná e que continua até hoje desconhecida" (MON, 2014, p.1). Em outra reportagem da Gazeta do Povo, o texto inicia lembrando a data de falecimento da artista. Vê-se que sua carreira é comparada ao aspecto "genial e trágico" de Miguel Bakun, que questiona as causas do desconhecimento de sua produção no contexto paranaense: "Seria o ostracismo voluntário? Seu temperamento firme? Sua posição de mulher, mãe e artista?". Ou melhor, considera-se que o seu esquecimento, infelizmente, expressa as regras do campo da arte em que parte de sua vida é “dramatizada” após sua morte.

Não houve sentimento do qual Hötte não tenha provado em doses cavalares - do desprezo à liberdade, tudo lhe diz respeito.

$[\ldots]$

Bela, culta, cheia da grana, estava licenciada para ter opinião e pavio curto. Aos 17, debutou... nos salóes de pintura. Nos doidos anos 1920, mudou-se para Berlim, onde cursou artes no Berliner Kunstgewerbermuseums. Provou das vanguardas estéticas.

$[\ldots]$

Bem, o que se sabe é que se casou com um alemão, deu à luz a Franz, até o casal travar uma guerra conjugal, no que era doutora. Em 1928, volta para o Brasil. Em 1932, divorcia-se. Suspeita-se que nunca arrefeceu o desejo de morar de novo na Europa. Crise após a crise - a de 1929, a da Segunda Guerra, foi ficando, por intermináveis décadas de espera.

Isolde poderia ter ostentado o título de melhor pintora de todas as araucárias, mas ser uma das primeiras divorciadas da paróquia deve ter reduzido, sei lá, o número de convites para jantar. Continuou pintando, não mais com Andersen, [...]. (FERNANDES, 2015, p. 01)

Prosseguindo o mapeamento do trabalho plástico desse grupo de 11 artistas com obras no MON, constata-se que os dados disponíveis na Enciclopédia não seguem um padrão de conteúdo, e sobre algumas artistas as informações são mínimas, como é o caso de Regina Oliveira (OLIVEIRA, 2021), que indica a sua atuação como atora e de Yara Martins, que divulga a mostra individual realizada em São Paulo, em 2004 (MARTINS,

\footnotetext{
${ }^{8}$ Isolde nasceu em 9 de outubro, em Curitiba; filha de pai alemão e mãe filha de suíços.
} 
2021). O vínculo com o Museu de Arte Contemporânea do Paraná, pelo site da Secretaria, também não tem registro a respeito da produção de ambas. De modo sumário, tem-se referência ao trabalho de Yara Martins pela mostra "O universo feminino de Alfredo Andersen", realizada em 2008.

O museu, como instância de educação não formal, contribui para que as obras de artistas atuantes em Curitiba sejam vistas pelo público, independente da linearidade temporal dos acervos, pois com obras no MON, elas são representantes de diferentes gerações como é o caso de Helena Wong, com produção artística associada às décadas de $1960^{9}$ e 1970 , bem como Teca Sandrini (SANDRINI, 2021), Elizabeth Titton (TITTON, 2021) e Guilmar Silva (SILVA, 2021), representantes da "geração 80".

Helena Wong, com nome de batismo Yuan Wong Mie, nasceu em Pequim, na China (1938), e faleceu em Curitiba (1990). A partir da década de 1950, reside no Brasil onde se naturaliza em 1962. No país, sua carreira artística se inicia durante a década de 1950, quando frequenta a Escola de Música e Belas Artes do Paraná (1950) e o ateliê de Thorstein Andersen (1953). Em 1963, conhece Ivan Serpa e começa a produzir na linguagem de gravura no Museu de Arte Moderna do Rio de Janeiro, realizando diversas exposições no transcorrer da década de 1960. Como referência imagética, a Enciclopédia apresenta a obra Pintura (1962) - manchas espatuladas com fundo branco acinzentado e onde, em primeiro plano, predomina o preto (WONG, 2021). Como destaque de sua trajetória, faz menção à exposição individual realizada no MASP (Museu de Arte de São Paulo Assis Chateaubriand), em 1965, assim como, a exposição inaugurada no MON (2005), com curadoria de Fernando Velloso.

No acervo do MAC/PR, tem-se a obra Ressureição ${ }^{10}$ (1965), que exibe a participação de Helena Wong no $1^{\circ}$ Salão de Arte Religiosa Brasileira. A partir de 1972, a artista volta a residir em Curitiba. Nesse mesmo ano, junto ao Museu de Arte Contemporânea do Paraná, participa da exposição coletiva “Paraná/arte/hoje”, realizada em parceria com a Prefeitura Municipal de Londrina e da Universidade Estadual de Londrina. Outra exposição coletiva que marca seu retorno ao Paraná é a mostra “Discípulos de Guido

\footnotetext{
${ }^{9}$ Na produção abstrata, Ana P. Silva (2006) analisa as obras Abstração X e Marinha, ambas de 1960; Desenho II (1963), do acervo MON; Primavera II (1965), acervo do MAC/PR.

${ }^{10} \mathrm{Na}$ técnica nanquim e giz de cera sobre papel, medindo $49,7 \times 59,8 \mathrm{~cm}$.
} 
Viaro", realizada no Teatro Paiol, em parceria com a Prefeitura Municipal de Curitiba e o Diretório Acadêmico Guido Viaro, da EMBAP.

Wong, ao longo da década de 1970, participa de várias exposições coletivas promovidas em parceria com o MAC/PR e outras instituições, como: Paraná/Arte/Hoje (1974); Arte Contemporânea no Paraná (1975); 22 artistas do Paraná (1976); Paraná Arte Agora (1976). Desse conjunto, representando a produção artística feminina, tem-se a

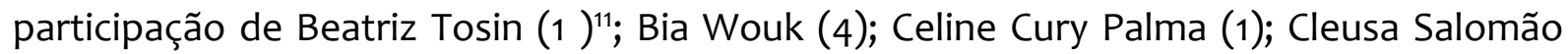
(1); Helena Wong (4); Ida Hanemann de Campos (4); Marcia Simões (1); Margarida Weisheimer (3); Sofia Diminski (1); Suzana Lobo (1); Suzanna Villela (3); Teresa Isabel Bakker (4); Violeta Franco (3); Victorina Sagboni (2).

A curitibana Estela Carmen Pereira Sandrini, conhecida no meio artístico paranaense como Teca Sandrini, nasceu em 1944, formou-se na Escola de Música e Belas Artes do Paraná em 1967. Suas primeiras exposições ocorrem no final da década de 1970 e ao longo da década de 1980. Além de artista e curadora, em 2017, exercia o cargo de diretora cultural do MON. A Enciclopédia destaca a participação de Sandrini em diversos certames artísticos, percurso que tem início em 1981 e avança até 2013. Destacam-se duas mostras individuais realizadas em São Paulo (SP) e em Campo Grande (MS), no Itaugaleria (1983), e outra coletiva (1992), realizada em Curitiba (SANDRINI, 2021). Teca dividiu a mostra com as obras de Guido Viaro e Guita Soifer.

Em 2006, Teca realiza a curadoria da mostra "Viaro: um visionário da arte", realizada no MON. Com base nos dados disponíveis no MAC/PR, em 1987, participa da exposição coletiva "Mostra de Jovens Gravadores de Curitiba"; em 1989, realiza a exposição individual "Desenho - pintura - gravura”, na Sala Theodoro De Bona. Como parte da sua produção, destaca-se a pintura Loucas Polacas II (1986), pela qual a artista recebe o prêmio no $43^{\circ}$ Salão Paranaense ${ }^{12}$.

Pela exposição de pinturas "Luzes que se apagam”, Sandrini expõe dez obras na Casa Andrade Muricy, dentre as quais uma pintura abstrata, com formas geometrizadas em uma rede de retângulos vistos em primeiro plano, em tom de cinza, que se mesclam com linhas pontiagudas ao fundo, induzindo à forma de triângulos. A paleta de cores

\footnotetext{
${ }^{11}$ Número de mostra que cada artista participou.

${ }^{12}$ Feita em nanquim e óleo sobre papel, medindo $102 \times 73 \mathrm{~cm}$.
} 
inclui o branco e o cinza, os tons de ocre e terra. A mostra foi organizada por Lenora Pedroso. Sobre sua trajetória artística, o destaque são as exposições individuais e internacionais, realizadas em 2002 e 2003. Além disso, o tema da exposição entra em sintonia com a música de Charles Chaplin e letra de Braguinha, conforme o trecho:

[...] como rever a trajetória com fome de pintura, de pintura como pintura, ingerindo tudo, textura, transparências, planos, cores, tonalidades, luz, sombras e gestos. A construção ou desconstrução, a estrutura ou a desestruturação, com tema ou sem tema. [...]. (CAM, 2006, p. 01)

Nascida na mesma década de Sandrini, em 1949, Elizabeth B. Dias Titton produziu na linguagem de escultura e participou do Salão Paranaense em 1981. Sinteticamente, este é o perfil profissional da artista de acordo com os dados disponíveis na Enciclopédia. Pela notícia divulgada no site da Secretaria de Cultura, a ênfase recai sobre seu percurso acadêmico e artístico:

[...] reside em Curitiba desde 1957. Formou-se em Administração de Empresas pela Universidade Federal do Paraná (UFPR) em 1973. Aos 30 anos, participou de um curso de férias no Centro de Criatividade São Lourenço. Decidiu, então, sair do emprego de administradora da Casa de Saúde São Francisco e dedicar-se à arte. Fez vestibular na Escola de Música e Belas Artes do Paraná (EMBAP), e, em 1982, concluiu a graduação em Pintura. No segundo ano de faculdade foi para Budapeste participar da V Bienal Internacional da Pequena Escultura, com máscaras de bronze. (AEN, 2016, p.01)

Especialista em Treinamento de Executivos Hospitalares pela UFPR (1975), em Sociologia e Economia (Perspectivas Históricas Contemporâneas), pela Pontifícia Universidade Católica do Paraná (1988) e Mestre em Educação, pela UFPR (2000). Titton foi diretora (1984-1987) e membro do conselho consultivo (2007) do MAC-PR (Museu de Arte Contemporânea do Paraná); criadora do espaço cultural Pró-Criar (1988), de onde é diretora até hoje; de 1990 a 2006, foi professora do curso superior de Escultura da EMBAP (AEN, 2016, p.1).

Durante a década de 1980, a artista participa de diversas mostras coletivas como “Valores atuais do Paraná: artistas premiados no $40^{\circ}$ e $41^{\circ}$ Salão Paranaense (1985)", 
“Escultura Paranaense Contemporânea: projetos cores e formas (1985)", bem como a

“Mostra de Jovens Gravadores de Curitiba (1987)”, realizada em São Paulo (Fundação Armando Álvares Penteado), Brasília (Fundação Cultural do Distrito Federal) e Florianópolis (Museu de Arte de Santa Catarina). Seu vínculo com os espaços expositivos do Paraná permanece ativo. Em 2008, participa da exposição “Coletiva de Escultores", realizada na Casa João Turin. Em 2012, Titton participa da mostra “Acervo MON - Novas aquisições", com a obra Árvore dos passarinhos (2007).

Assim como Jussara Age, Uiara Bartira e Titton, Guilmar Maria Vieira Silva participa da exposição "Valores atuais do Paraná: Artistas premiados no $40^{\circ}$ e $41^{\circ}$ Salão Paranaense". A artista nasceu em 1943, em Balneário Camboriú-SC, e faleceu em 2008, em Curitiba. Durante seu percurso artístico, participou de várias coletivas no decorrer das décadas de 1980 e 1990, dentre as quais a "Mostra de Gravura da Cidade de Curitiba" (1984 e 1988); o "Salão de Arte de Ribeirão Preto", em Ribeirão Preto-SP (1990); a exposição do acervo do Museu Municipal de Arte em 1991. Como referência de sua produção imagética, menciona-se a obra Identidades paralelas¹3 (SILVA, 2021).

\section{Considerações finais}

Em síntese, o MON adotou como política de aquisição do seu acervo, no período de 2003 a 2011, a doação por parte dos artistas das obras que faziam parte das exposições realizadas no próprio museu (VAZ, 2011). O museu totalizava 2.585 obras, das quais 652 delas foram adquiridas na gestão de Maristela Requião, perfazendo 89 artistas (VAZ, 2011). Desse total, tem-se 20 artistas mulheres no montante de 386 obras, conforme sintetizado no quadro 1. Quanto ao percurso das artistas mulheres locais entre o mercado comercial e a aceitação oficial, o número se reduz, de 22 artistas que participam das galerias intermediárias, para 11, que vinculam suas obras no MON, sendo que 25 mulheres que expuseram somente nas galerias comerciais não conquistaram a posição oficial, conforme quadro 2. Portanto, o reconhecimento oficial está atrelado ao valor simbólico das artistas, expresso pelas exposições promovidas pela FCC e SEEC - defasagem simbólica visível na participação das artistas entre os tipos de galerias.

\footnotetext{
13 Pintura abstrata, branca, texturizada com massa acrílica e pequenos recortes de papel sobre papel, medindo $44,2 \times 29,5 \mathrm{~cm}$.
} 
O valor simbólico da arte que rege o funcionamento do campo artístico ajusta-se ao habitus do grupo. Além disso, uma parcela das imagens produzidas por essas mulheres com aceitação oficial revela uma arte dócil, que não problematiza a questão de gênero e nem mesmo se enquadra em uma produção de cunho feminista. As obras citadas são abstratas e/ou figurativas, com temas que retratam a natureza-morta, o retrato de mulheres, as cenas em família. Temáticas relacionadas ao machismo, à violência sexual, à invisibilidade da mulher no mercado de trabalho não fazem parte do repertório imagético do grupo feminino, tendo em vista a parcela das obras analisadas. Nesse aspecto, ascender ao mercado oficial exige compreender as regras do campo artístico, em que as lutas feministas, de certo modo, não se ajustam aos dogmas que regem uma "arte pela arte", ou seja, uma arte que é descolada do social e dos problemas concretos do mundo vivido. Em que discutir gênero é criar estratégias para romper com o modelo patriarcal, que ainda rege o habitus de grande parte das pessoas que participam do universo da arte e de outras esferas de poder, e, talvez, correr o risco de não ser "aceita" em espaços conservadores ou legitimados por gestores homens.

\section{Referências}

AEN. Elizabeth Titton conduz oficinas para visitantes do MON. Agência de notícias do Paraná. Curitiba, 2016. Disponível em:

https://www.aen.pr.gov.br/modules/noticias/article.php?storyid=89779. Acesso em: 9 jul. 2021.

AGE, Jussara. In: ENCICLOPÉDIA Itaú Cultural de Arte e Cultura Brasileiras. São Paulo: Itaú Cultural, 2021. Disponível em:

http://enciclopedia.itaucultural.org.br/pessoa269285/jussara-age. Acesso em: 1 dez. 2018.

BARBOSA, Ana Mae. Uma questão de política cultural: mulheres artistas, artesãs, designers e arte/educadoras. In: ENCONTRO DA ASSOCIAÇÃO NACIONAL DE PESQUISADORES EM ARTE PLÁSTICAS, 19., 2010, Bahia. Anais [...]. Cachoeira: Anpap, 2010. p. 1978-1988. Disponível em:

http://anpap.org.br/anais/2010/pdf/ceav/anna_mae_tavares_bastos_barbosa.pdf. Acesso em: 2 abr. 2018. 
BARTIRA, Uiara. In: ENCICLOPÉDIA Itaú Cultural de Arte e Cultura Brasileiras. São Paulo: Itaú Cultural, 2021. Disponível em:

http://enciclopedia.itaucultural.org.br/pessoa19949/uiara-bartira. Acesso em: 1 dez. 2017.

BATISTA, Stephanie Dahn. 0 corpo falante: as inscrições discursivas do corpo na pintura acadêmica brasileira no século XIX. Tese (Doutorado em História) - Universidade Federal do Paraná, Curitiba, 2011.

BATISTA, Valdoni Ribeiro; RAUEN, Margarida Gandara. A desarticulação do androcentrismo e da discriminação interseccional por meio do ensino da arte contemporânea. PÓS: Revista do Programa de Pós-graduação em Artes, Belo Horizonte: EBA/UFMG, v. 7, n. 14, p.72-91, 2017.

BOURDIEU, Pierre. A dominação masculina. Tradução Maria Helena Kühner. 6. ed. Rio de Janeiro: Bertrand Brasil, 2009.

BOURDIEU, Pierre. As regras da arte: gênese e estrutura do campo literário. Tradução Maria Lucia Machado. 1. ed. São Paulo: Companhia das Letras, 1996.

CAM. Luzes que se apagam. [Curitiba]: CAM, 2006. Disponível em: http://www.cam.cultura.pr.gov.br/modules/conteudo/conteudo.php?conteudo=27. Acesso em: 1 dez. 2017.

CATANI, Afranio Mendes As possibilidades analíticas da noção de campo social. Educ. Soc., Campinas, v. 32, n. 114, p. 189-202, jan./mar. 2011.

D'ASSUMPÇÃO, Maria Amelia. In: ENCICLOPÉDIA Itaú Cultural de Arte e Cultura Brasileiras. São Paulo: Itaú Cultural, 2021. Disponível em:

http://enciclopedia.itaucultural.org.br/pessoa23940/maria-amelia-dassumpcao. Acesso em: 1 dez 2017.

DEL VECHIO, Annalice. Extraordinária e marginal. Gazeta do Povo, Curitiba, 2010. Caderno G. Disponível em: http://www.gazetadopovo.com.br/caderno-g/extraordinaria-e-marginal14gmbleo8jk6rnxyb3q4j2wcu. Acesso em: 1 dez. 2017.

FANINI, Michele Asmar. Nem excepcionais, nem amadoras: artistas profissionais. História, São Paulo, v. 28, n. 2, p. 871-877, 2009.

FERNANDES, Jose Carlos. Acervo 2: o solo de Isolde Hotter. Gazeta do Povo, Curitiba, 3 jan. 2015. Disponível em: http://www.gazetadopovo.com.br/vida-ecidadania/colunistas/jose-carlos-fernandes/acervo-2-o-solo-de-isolde-hottechrazxvd4xa4tjzrucialgs52. Acesso em: 1 dez. 2017.

FILHO DOMINGOS, Doacir. A diversidade de gênero em materiais didáticos da disciplina de arte. Dissertação (Mestrado em Educação) - Universidade Estadual Centro-Oeste, Guarapuava, 2018. 
FONSECA, Rui Pedro. Carreira, arte feminista e mecenato: uma abordagem à dimensão económica do circuito artístico principal sob uma perspectiva de género. Sociologia, Revista da Faculdade de Letras da Universidade do Porto, Porto, v. XXVI, p. 113-137, 2013b.

FONSECA, Rui Pedro. Condições de produção dos feminismos artísticos em Portugal. Estudos Feministas, Florianópolis, v. 21, n. 3, p. 1015-1038, $2013 a$.

HOTTE, Isolde. In: ENCICLOPÉDIA Itaú Cultural de Arte e Cultura Brasileiras. São Paulo: Itaú Cultural, 2021. Disponível em:

http://enciclopedia.itaucultural.org.br/pessoa597942/isolde-hoette. Acesso em: $1^{\circ}$ dez. 2017.

LOPONTE, Luciana Gruppelli. Sexualidades, artes visuais e poder: pedagogias visuais do feminino. Estudos Feministas, Florianópolis, v. 10, p. 283-300, 2002.

MON. Isolde Hötte, sua obra. Sala de referência do acervo e da ação educativa. [Curitiba]: MON, 2014. Disponível em:

https://www.museuoscarniemeyer.org.br/exposicoes/exposicoes/isoldehotte. Acesso em: 9 jul.2021.

OLIVEIRA, Regina. In: ENCICLOPÉDIA Itaú Cultural de Arte e Cultura Brasileiras. São Paulo: Itaú Cultural, 2021. Disponível em:

http://enciclopedia.itaucultural.org.br/pessoa423883/regina-oliveira. Acesso em: 1 dez 2017.

OSINSKI, Dulce. In: ENCICLOPÉDIA Itaú Cultural de Arte e Cultura Brasileiras. São Paulo: Itaú Cultural, 2021. Disponível em:

http://enciclopedia.itaucultural.org.br/pessoa10193/dulce-

osinski;\%2ohttp://www.mac.pr.gov.br/modules/galeria/detalhe.php>. Acesso em: $1 \mathrm{dez}$ 2017.

SALTURI, Luis Afonso. Gerações de artistas plásticos e suas práticas: sociologia da arte paranaense das primeiras décadas do século XX. Tese (Doutorado em Sociologia) Universidade Federal do Paraná, Curitiba, 2011.

SANDRINI, Estela. Desenho, pintura, gravura. [Curitiba]: MAC, 1989. Disponível em: http://www.mac.pr.gov.br/modules/conteudo/conteudo.php?conteudo=81. Acesso em: 1 dez. 2017.

SANDRINI, Estela. In: ENCICLOPÉDIA Itaú Cultural de Arte e Cultura Brasileiras. São Paulo: Itaú Cultural, 2021. Disponível em:

http://enciclopedia.itaucultural.org.br/pessoa10052/estela-sandrini>. Acesso em: 1 dez 2017.

SILVA, Ana Paula França Carneiro da. Abstração em Helena Wong - 1960 a 1965. In: FÓRUM DE PESQUISA CIENTÍFICA, 4., 2016, Curitiba. Anais [...]. Curitiba: Arte Escola de Música e Belas Artes do Paraná, 2006. Disponível em: 
http://www.embap.pr.gov.br/arquivos/File/anais4/ana_paula_silva.pdf. Acesso em: 1 dez 2017.

SILVA, Guilmar. In: ENCICLOPÉDIA Itaú Cultural de Arte e Cultura Brasileiras. São Paulo: Itaú Cultural, 2021. Disponível em:

http://enciclopedia.itaucultural.org.br/pessoa4246/guilmar-

silva;\%2ohttp://www.mac.pr.gov.br/modules/galeria/detalhe.php. Acesso em: 1 dez. 2017.

TITTON, Elizabeth. In: ENCICLOPÉDIA Itaú Cultural de Arte e Cultura Brasileiras. São Paulo: Itaú Cultural, 2021. Disponível em:

http://enciclopedia.itaucultural.org.br/pessoa217676/elizabeth-

titton;\%2ohttp://www.cultura.pr.gov.br/modules/noticias/article.php. Acesso em: 1 dez. 2017.

VAZ, Adriana. Artistas plásticos e galerias de arte em Curitiba: consagração simbólica e comercial. 2004. 284f. Dissertação (Mestrado) - Universidade Federal do Paraná, Curitiba.

VAZ, Adriana. O Museu Oscar Niemeyer e seu público: Articulações entre o culto, o massivo e o popular. 2011. 377f. Tese (Doutorado em Sociologia) - Universidade Federal do Paraná, Curitiba.

WONG, Helena. In: ENCICLOPÉDIA Itaú Cultural de Arte e Cultura Brasileiras. São Paulo: Itaú Cultural, 2021. Disponível em:

http://enciclopedia.itaucultural.org.br/pessoa9472/helena-

wong;\%2ohttp://www.mac.pr.gov.br/modules/galeria/detalhe.php. Acesso em: 1 dez 2017.

YARA, Martins. In: ENCICLOPÉDIA Itaú Cultural de Arte e Cultura Brasileiras. São Paulo: Itaú Cultural, 2021. Disponível em:

http://enciclopedia.itaucultural.org.br/pessoa389343/yara-

martins;\%2ohttp://www.cultura.pr.gov.br/modules/noticias/article.php. Acesso em: $1 \mathrm{dez}$ 2017.

Recebido em: 30/08/2019

Revisões requeridas em: 12/12/2020

Aprovado em: 22/02/2021

Universidade do Estado de Santa Catarina - UDESC Programa de Pós-Graduação em Educação - PPGE

Revista Linhas

Volume 22 - Número 49 - Ano 2021

revistalinhas@gmail.com 